\title{
Location-based Storytelling in the Urban Environment
}

\author{
Jeni Paay ${ }^{1,2}$ and Jesper Kjeldskov ${ }^{1,2}$ with Anders Christensen², Andreas lbsen², \\ Dan Jensen ${ }^{2}$, Glen Nielsen ${ }^{2}$ and René Vutborg ${ }^{2}$ \\ ${ }^{1}$ User Experience Group, CSIRO ICT Centre, Marsfield, NSW, 2122, Australia \\ ${ }^{2}$ Department of Computer Science, Aalborg University, Selma Lagerlöfs Vej 300, 9220 Aalborg E, Denmark \\ Jeni.Paay@csiro.au, Jesper.Kjeldskov@csiro.au
}

\begin{abstract}
Reality is everywhere. It is right there in our face when we wake up and it continues to sneak up on us throughout our day, in the car, in our offices, and at the dinner table. In recent years it has even invaded our TVs through eternal news streams and endlessly boring reality TV shows. However, people cannot live by reality alone. In fact, we spend quite a lot off effort on escaping reality. We daydream and immerse ourselves in imaginary worlds and stories. We immerse ourselves in fiction. Inspired by this view, we report on our research into the design and user experience of a new genre of mobile location-based services, which uses peoples' physical surroundings as a backdrop for storytelling as they move around an urban environment. We present a prototype system developed to explore the user experience of location-based interactive stories, and the use of interaction designs aimed at blurring the boundary between reality and fiction. Based on qualitative data from a series of field trials, we discuss potentials and challenges for this class of location-based services.
\end{abstract}

\section{Categories and Subject Descriptors}

H5.2. [Information interfaces and presentation (e.g., HCI)]: User Interfaces - User-centred design

\section{General Terms}

Design, Human Factors.

\section{Keywords}

Pervasive Computing, Location-Based Services, Interactive Narratives, Urban Spaces, Fiction.

\section{INTRODUCTION}

Imagine if the city could tell its story. Let us move away from the generally accepted idea of a mobile city guide as presenting users with pure facts about their surroundings, to a more engaging experience, which responds to users' current location and adds value to being mobile by turning city streets into the stage on which a story unfolds. By taking an orthogonal approach to mobile guides, we propose the provision of nongoal directed user experience that weaves fictional stories around existing physical, historical and environmental elements of users' immediate surrounds as they move through the city.

OZCHI 2008, December 8-12, 2008, Cairns, QLD, Australia. Copyright the author(s) and CHISIG. Additional copies can be ordered from CHISIG (secretary@chisig.org).

OZCHI 2008 Proceedings ISBN: 0-9803063-4-5
In our recent research, we have been exploring the design, implementation, and user experience of context-aware and location-based mobile information services, which "augment the city" with a digital layer of information about, for example, people, places and the users' physical surroundings [14]. Common for our research has been that the systems and services explored have provided users with factual information, that would otherwise be invisible, from which people could then decide what to do while socialising out on the town; where to go, how to get there, what to do there, who to meet up with etc. In many ways, this matches the majority of research and design being done within the area of mobile guides: providing users on the move with facts about the reality that they are in. However, let's face it, people cannot live by reality alone! Reality is everywhere. It is right there in our face when we wake up in the morning, and it continues to sneak up on us throughout our day, in the car, in our offices, in the tearoom, and at the dinner table. In recent years it has even invaded our TVs; not only through eternal streams of live news from wherever, but also through endlessly boring reality TV shows documenting minute-by-minute details of peoples' mundane lives. Perhaps this is why we spend quite a lot of effort (and money) on escaping reality. We daydream, we go to the cinema, we rent a video, or we read or listen to a book. We like to immerse ourselves in imaginary worlds and stories as way of escaping every day life. People need wonderment [19]. We like to immerse ourselves in fiction.

So why not let mobile guides provide people with fiction about their physical surroundings rather than just facts? Inspired by this question, we have engaged ourselves with a stream of research exploring the user experiences achieved by "augmenting the city with fiction" in a way that is playful, ambiguous [9] and opaque rather than goal-oriented and transparent. This evokes some fundamental questions. How can mobile guides provide for peoples' desire for fictional content? How can quality storytelling benefit from its listeners being on the move or located in a particular place? How can we characterise different types of context-aware or location-based stories? How can we narrate engaging stories, which take into consideration the listener's location, movements over time, and perhaps even social context? How can we design and implement useable media for this genre of storytelling?

\section{BACKGROUND}

Advances in mobile information and communication technologies have made the mobile Internet fast, relatively cheap, and widely accessible in most populated areas of Australia. However, truly useful mobile Internet services are still rare and, as a consequence, a recent survey of Australian consumer patterns released by Ericsson Australia concludes that 
while Australians are increasingly interested in the mobile Internet, very few are actually using it (Ericsson 2007).

There are several explanations for peoples' limited uptake of the mobile Internet. Most importantly in our eyes, we have simply not yet offered content to interested and eager potential users worth accessing and paying for while on the move! The mobile Internet is not just about doing, while moving, things we used to do at our desktop, such as accessing our email - it is about enabling people to do things that couldn't be done before, and it provides the opportunity to establish a relationship between digital media and the environment in which it is being accessed. Hence, if the use of mobile Internet technologies is to have a higher uptake, we must provide people on the move with applications giving them easily obtainable added value. It is our belief that facilitating peoples' non-goal directed social needs relating to experiences, enjoyment and recreation is a potential area for such new applications, and that tailoring them to peoples' location can help differentiate mobile Internet applications from traditional, wired, ones.

Location Based Services (LBS) represent an emerging class of information systems providing mobile users with information tailored to their geographical location. LBS have been receiving increasing attention from researchers and the software industry because they open up opportunities for developing new services and experiences for users on the move. Supporting this course from the users' side, "positioning services" have been identified as the top-most mobile Internet service of interest among 2000 Australians surveyed [8]. While examples of commercially available services are still very few, new advances in technology are fuelling the development of more advanced services. PDAs and $3 \mathrm{G}$ mobile phones with built-in GPS and other positioning capabilities have become affordable and popular, and providers have begun offering services that integrate wide-area broadband wireless Internet access, web resources and geographical information. Contributing to this it was recently announced that the next generation of Apple iPhones will ship with built-in GPS and be supported by development software enabling the creation of advanced location-based services such as mobile guides and games.

\subsection{Mobile Guides and Mobile Gaming}

Our research is inspired by a range of projects within the areas of mobile guides and mobile games. In common with our own project is the aim to provide engaging and enriching experience to users on the move. Early context-aware mobile guides such as Cyberguide [1], the Lancaster GUIDE [7] and Hippie [18] provided visitors, city travellers and museum tourists with location-based experiences which included pertinent information and guidance about their current location, but did not focus on narrative issues. However they acted as valuable vehicles for exploring and understanding important fundamental interaction and technical issues about the design of mobile guides.

Location-based mobile games such as Pirates! [4], ARQuake [20], and Can You See Me Now? [2] offer inspiration for new potential applications of location-based technologies. They are also valuable vehicles for studying interaction design for emerging context-aware technologies designed to operate 'in the wild'. In particular, Can You See Me Now?, with its engaging artistic experience of seamlessly connecting online players in a virtual world to play against real players in the actual city, demonstrates new potentials for human interaction with computers and with each other.

Beyond these applications that provide users with engaging gaming experiences, is the emerging area of location-based games that also incorporate stories into the mix in order to enhance the user experience. Backseat Playground [13] provides a narrated experience interweaving a crime mystery, visible physical elements of the environment, and gaming for children sitting in the back seat of a car while on a journey. Uncle Roy All Around You [3] is a programmed game that involves the surrounding city, live actors, online and street players to follow a set of pre-scripted clues to find Uncle Roy's office.

The delivery of location-based histories using mobile technology is another area of research, which includes applications such as Riot! [5], Hopstory [17], and Geist [16]. Riot! delivers authored episodes triggered by specific locations about an historical riot that happened in and around Queens Square. Hopstory allows visitors to an historic brewery to collect location related history based video vignettes as they navigate the building. Geist provides an augmented reality experience for visitors to the city of Heidelberg, using history to allow the viewer to experience how it felt to be in that city during the 30 Years' War in the 17th century. These applications are the most inspiring for our current research as they provide experience and understanding of peoples' responses to an environment augmented with narrative.

\subsection{Fiction in the City}

Anecdotally, peoples' desire for storytelling and important aspects of that fiction can be seen in popular stories of our time. Many best-selling novels illustrate the appeal of blurring of boundaries between fact and fiction, supporting the need for the "suspension of disbelief" in story telling. The Da Vinci Code [6] sold over 60.5 million copies, was translated into 44 languages world-wide, is the thirteenth best selling book of all time, and inspired a feature-length movie which was the second highest grossing movie of 2006, world-wide. The Da Vinci Code establishes its sense of intrigue and allurement from a clever interweaving of things that we know to be historical facts and real places with "believable" stories involving these elements. Crime fiction becomes all the more evocative when it locates its scenes in places that we are familiar with, and invites us to believe that this has happened in that location. For example, crime stories by Melbourne writer, Kerry Greenwood, about a Melbourne baker $[10,11,12]$ walks us through the streets of Melbourne and possibilities of dark happenings that we are unaware might be occurring in the city we think we know so well. This technique is also brought into play in Riot! [5], Hopstory [17], and Geist [16].

Further supporting our understanding that people are looking for aural input while on the move is the meteoric rise in popularity of the iPod, mp3 players generally, and now mobile phones with audio listening capabilities to supplement and even disconnect people from their daily realities. This has recently been extended beyond music to the downloading of pod-casts and e-books to add an element of storytelling to our lives in situations where we have previously had to resort to the printed word (i.e. on the way to work in the train) or centrally controlled broadcast media and narratives (i.e. listening to the radio while driving). Now we can decide what we want to listen 
to and where - so why not take this further and incorporate our surrounding environment into the story.

\section{WHO KIIUEDHANNE HOLMGAARD?}

In order to explore the user experience of location based fiction in the city we built a prototype system called "Who Killed Hanne Holmgaard?". This system was designed to operate in the city of Aalborg, in Northern Jutland in Denmark. Aalborg is a city which traces its history back over 1,000 years and is today a mixture of old and new precincts, including streets of modern shops around the new town square abutting historical churches, civic buildings, a brewery, and a convent around an old town square. Aalborg is also a city that is easily accessible by foot, and has multiple pedestrian streets and plazas that form an alternate network to the busy vehicular streets. These factors make Aalborg a good city for trialling a location-based storytelling system using the physical environment surrounding the user as a backdrop.

The development took place over four months in late 2007 and involved a design and development team of five people with a background in informatics and computer science under the overall management by two senior HCI researchers.

\subsection{Creating the Storyline}

Through a process of brainstorming, bodystorming in city streets, and sketching, the design group decided to create the story in the genre of a historical murder mystery set during World War II and situated in and around the streets of Aalborg. The system was designed for computer supported collaborative play, in that two participants experienced the story by working cooperatively to unravel the mystery while on the move. Each participant plays a different character in the story, and these two characters must work together to solve the crime. The system is location based, responding to the user's current location providing the episodes of the storyline related to that location. The interactive story, accessed using two networked PDAs, introduces the two participants to the characters they are playing, the other fictional characters in the story, episodic plot lines that interweave both fiction and fact, clues and logical puzzles that lead them through the story and through the city.

The inspiration for the storyline for Who Killed Hanne Holmgaard? was an historical account about the lives of two famous police officers in Aalborg in the 1940s, called "Det gamle Aalborg på vrangen" (trans: "The Hidden Side of Aalborg") [15]. This book describes what it was like to be a police officer during this time, detailing how they dealt with everything from illicit bars, to prostitutes, to excessive gambling. The book details the consequences of the German Military Forces' takeover of the Danish police force towards the end of World War II in September 1944. By setting the story during the German occupation of Denmark we were able to introduce colourful characters into the storyline such as illicit bar owners, prostitutes, gamblers, members of the resistance and Nazis. We also used the names of the two police officers from the book, "Tall Anton" and "The Wrestler" for the main characters in the story. The story unfolds around these two detectives pursuit of solving the mystery of the untimely and unnatural death of a young Nun, Hanne, found lying in a dark alley in the city, on an early rainy winter's morning.

\subsection{Integrating the Urban Environment}

An important part of our concept was to integrate and inspire the story with the physical environment of the city of Aalborg. A second bodystorming design session was held in Aalborg city to scope out convincing locations in the older part of the city where events (both fictional and factual) may have taken place in the 1940s, including the old convent in the centre of the city, a nearby cathedral school, the old town hall and some old narrow alleyways. Setting the story in the 1940s during the German occupation made some locations, such as the convent that was a headquarters of the local resistance towards the end of the war, key contenders for inclusion in our story.

After outlining a background story, we built up profiles of all the characters including the two detectives, suspects etc. and created scene descriptions for all of the key locations. Although the whole murder story was entirely fictional, many of the subplots, and the establishment of character motivations and alibis of our protagonists were based on historical events of the time.

\subsection{Designing user interface and interaction}

The user experience and user interaction with the system was designed using sketching, mockups, and paper prototypes (e.g. figure 1) in parallel with the story writing activity. We wanted to combine the digital elements of the story with tangible interactions with real-world locations and objects such as inscriptions and symbols on buildings, paper maps, and physical props similar to what might be found in a theatre production of the story. We also wanted these props to tie the digital story elements closely to the physical surroundings and to create a fuzzy boundary between the story and the environment in which the user was located. As an example of this, we explored the idea of providing the users with a $1940 \mathrm{~s}$ style paper map of Aalborg annotated with symbols, which could be used to direct the users to walk to particular locations in the city at key points of the story. Other props explored included marked envelopes with physical evidence or clues to be opened at particular points of the story, and to be passed between the users. Another approach explored to tie the digital experience closely to the physical surroundings was the use of printed photographs of actual locations in the user's current surroundings overlaid with fictional characters and objects from the storyline. Physically lining up the photographs and the physical surroundings, and indexing between the two, brings characters and objects from the story into the physical location through the imagination of the user.
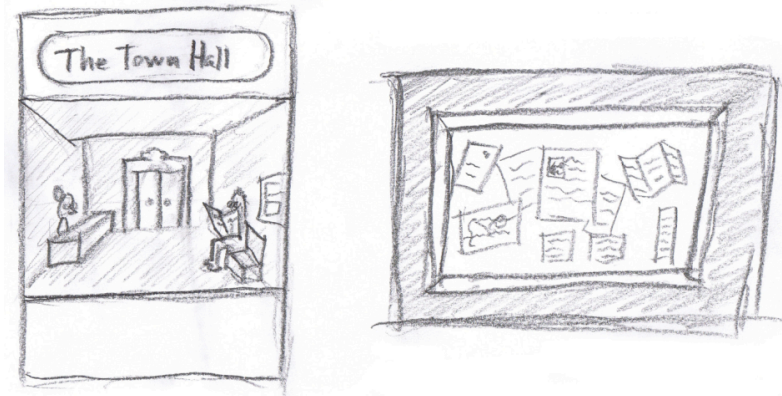

Figure 1. Early design sketches for displaying of interactive story elements on the PDA 


\subsection{The User Experience}

Who Killed Hanne Holmgaard? is experienced simultaneously by two people each equipped with a PDA and a headset (figure 2). The two participants are also provided with a physical map of the centre of Aalborg, and with a shoulder bag containing a number of sealed marked envelopes. In order to engage with the story, the participants have to physically walk around the city visiting key locations in the story in a particular order as the story unfolds. Apart from the starting location, the order of locations is not revealed beforehand. The story is told using audio, pictures and text. Narration is provided both verbally and textually. Interaction is primarily done by moving physically through the city but also by selecting choices on the screen.

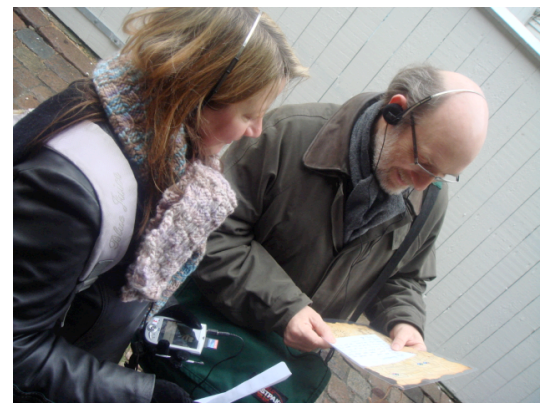

Figure 2. Engaging with fiction in the city through two individual PDAs with headsets.

\subsubsection{Shared interaction and individual discourses}

The overall setting of the story is that two users play two detectives from the capital of Denmark, "Tall Anton" and "The Wrestler", who have been assigned to the case of a murder in the provisional city of Aalborg towards the end of World War II. In the opening scene users are introduced to the crime scene and given some initial clues and evidence from the local police officer in charge. From then on they are collaboratively working their way through the story, which takes them through the physical city centre of Aalborg and make you encounter a series of fictional characters.

While following an overall linear structure, allowing the use of classic storytelling techniques such as point of no return, curve of tension, plot, etc, the story contains a series of interactive elements where the two users have to make choices between possible paths. This is done either collaboratively or individually. Acting as two different characters, the two people engaged with the story are at different points allowed or forced to split up from the shared storyline and follow individual discourses. Most often this takes place in the form of interrogating two different characters in the story in parallel or taking lead in the pursuit of a particular clue. In order to ensure tension, neither of the two detectives is given enough information to solve the crime. As a designed consequence of this, the two people engaged with the story have to engage closely with each other to experience the whole narrative and gain an overall understanding of the plot, reporting back from their individual discourses, and discussing and reflecting collaboratively on the meaning of what they have each learned. Based on this, they have to decide together on strategies and choices for how to proceed.

The story unfolds as the two detectives move through the city, and is triggered by their arrival at specific key places. Each of these places has one or more specific episodes of the story attached to them, which will then be presented depending on what part of the story the participants are up to. When the participants come to the final location in the convent garden, their characters are given a final chance to question witnesses and suspects before they are prompted to discuss and make a joint considered decision about who their main suspect is. After they have done this, the system will play out the final scene and disclose the perpetrator.

\subsubsection{Auditory and visual design}

The user experience is driven through an audio track with narration, dialogue and sound effects. Holophonic sound is used to create an ambient soundscape to enhance the experience of the story in situ. For example, the sound of rain through the headsets is designed to blend with the sounds from the physical surroundings making it hard to separate the two and adding to the overall feeling that you are 'in' the story. In parallel with the spoken narrative, the PDAs display photographs from the user's current location superimposed with fictional characters from the scene and text matching the soundtrack for visual persistency. The background photographs are in black and white while the characters, and other interactive elements, are in colour (figure 3 ). The use of photographs creates indexes between the storyline and the surrounding environment and also confirms to the users that they are in the right place.
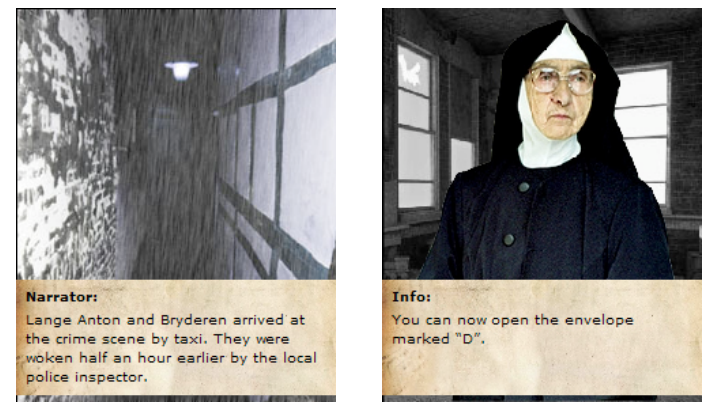

Figure 3. The opening screen displaying a historical alley in Aalborg where Hanne was found dead (left), and a fictional character passing on a piece of evidence (right).

\subsubsection{Interactive story elements}

At each location of the narrative, there is a variety of ways that the participants can interact with the story line. The primary form of interaction takes place through questioning of witnesses or suspects. This is done through selection from a number of predefined questions presented on the screen (figure 4). Since the two detectives have very different personalities, their vocabulary of questions, and the tones by which that are asked, differ substantially. As a natural consequence, so do the responses. Hence, it makes a difference how the two detectives divide the witnesses and suspects between themselves, and sometimes both detectives will have to interview the same character to get the full picture.

Other interactive story elements include discovering hotspots with important information on the screen (such as a significant news paper story posted on a pinup board in an office), or solving a small puzzle to gain a clue, such as physically piecing together a torn letter uncovered in pieces at different locations throughout the story. 

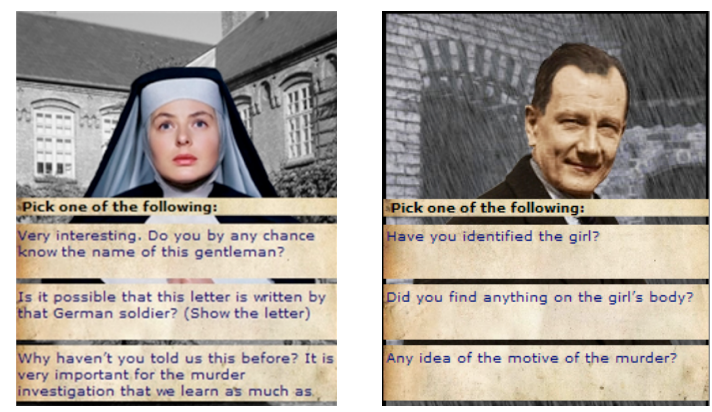

Figure 4. Interactive story element with choices of questions during the interrogation of a witness. The character is overlaid on a picture from the user's current location.

\subsubsection{Physical props}

A series of physical props are introduced through the story, enhancing the interactivity of the story creating a fuzzy boundary between the story and the physical context in which it is being experienced. The primary physical props are introduced into the narrative through prompts in the storyline instructing the users to open particular envelopes in the shoulder bag handed to them at the beginning. The envelopes contain different elements such as photographs and hand written letters designed to enhance the experience of the story and provide important clues for solving the murder (figure 5).

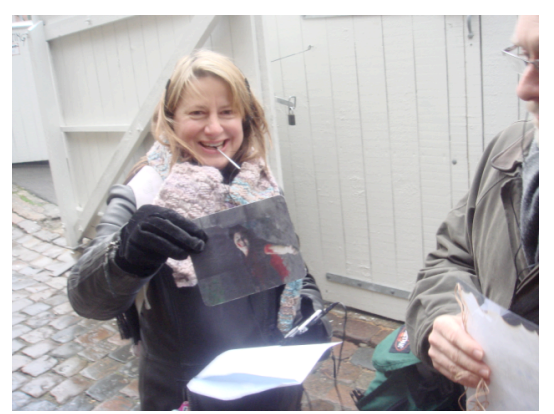

Figure 5. Integrating physical props into the story: when arriving at the scene of the crime, the detectives are given a set of photograph of the victim in a pool of blood.

Another physical prop designed to blur the boundary between virtual and physical is the passing of a physical note from a character in the story to one of the detectives. This is done through a combination of narration and prompting the user to pull out the small piece of paper from a pocket attached to the back of their PDA. By keeping the passed note physical rather than just displaying the text on the screen, it is later used in conjunction with one of the other physical props to provide a final clue. As another example of blurring the boundary between virtual and physical, some props can be used in interrogations by "showing them to the character on the screen" by physically holding it in front of the person depicted on the PDA. A third use of physical props is the use an old paper map of the city of Aalborg to guide the detectives to particular places in the city for the next scene of the story.

\subsubsection{Proceeding from one scene to the next}

Once the two detectives have gathered enough pieces of information at a particular location they are prompted to move on to the next scene at a different place. Rather than providing way-finding information on the PDAs for this purpose, the users are provided with a physical map of the city with key locations of the story highlighted. However, in order to keep the path through the city flexible and secret, each location is annotated with a unique symbol rather than numbers or letters, making it impossible for the detectives to know where to go next. Increasing the challenge, the correct symbol can only be obtained through collaboration. Based on the information gathered from individual interrogations, each detective will at some point in time be provided with half the symbol needed to move on. Only when both halves have been obtained is it possible for the two participants to work out where to go to next by locating the corresponding composite symbol on the physical map (figure 6).

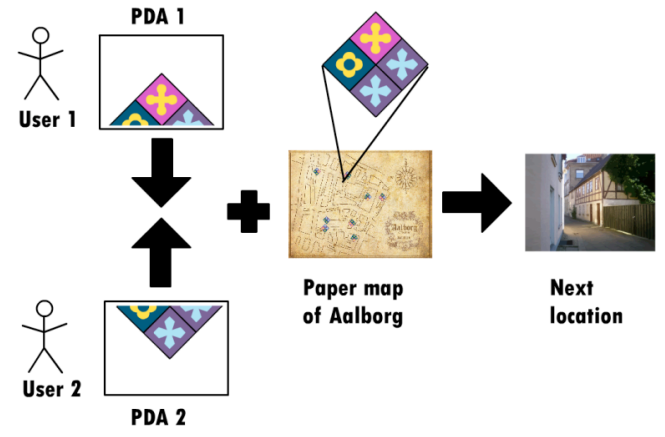

Figure 6. Finding the next location of the story from a composite symbol and a physical map.

Revealing the composite symbol is done by physically holding the two PDAs together (figure 7).

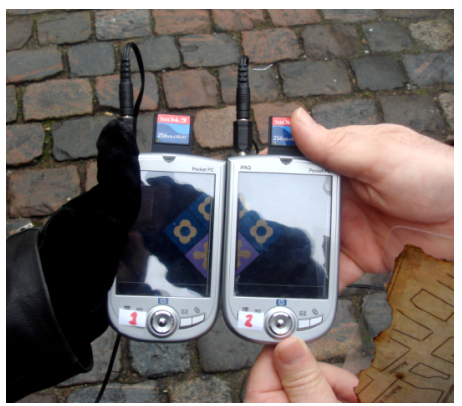

Figure 7. Physically aligning PDAs to reveal the symbol needed to work out the location of the next scene.

The encoding of different places on the map using symbols keeps the participants unaware of where the next location will be, and controls their progress through the city. The symbols are graphically designed so that the whole symbol cannot be inferred from any half.

\section{FIELD TRIALS}

Two HP iPAQ PDAs were used to build a working prototype. The prototype software was created using an Apache Web server, the PHP scripting language and Adobe Flash for the visual appearance of the scenes. The two PDAs used wireless network cards to communicate with a laptop computer that acted as a wireless access point during the evaluations. This laptop was carried in a backpack by one of the evaluators who stayed close to the test subjects. An iPod with Wi-Fi and an Internet browser was used to control the states of the two participants' PDAs in a Wizard of $\mathrm{Oz}$ fashion (figure 8). 
The purpose of the evaluation was to obtain feedback on the user experience with the Who Killed Hanne Holmgaard? system. Issues regarding the usability of the system were not a priority. Three story episodes from the overall 11 episodes of the system were implemented in detail in the prototype system, with bridging text for story coherence, and used in a field trial of the system. Five pairs of participants were given the story experience in situ in the city of Aalborg. Three members of the development team accompanied the pairs through the city. The trial experience of the prototype system took about 90 minutes. The participants ranged in age from 17 to 62 , were of mixed gender, and ranged in computing experience from limited to IT professional. Three of the participants came from outside Denmark and the others were residents of Aalborg.

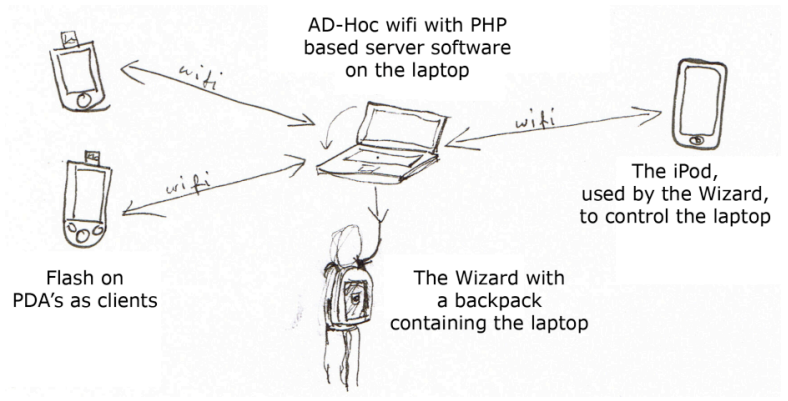

Figure 8. Technical set-up of the prototype.

The evaluation started with an introduction to the participants about how the trial would proceed. Participants were informed that this was an interactive story told using PDAs and headsets at different locations around the city. They were then given the necessary equipment for the trial: a PDA each, a headset, a shoulder bag containing sealed marked envelopes, and a map of the centre of Aalborg. To give them some background information about the story, they were each given a text description of their character and a short introduction to the context of the story. They were then prompted to begin. To find their start location, they had to align the two half symbols displayed on their respective PDAs, locate this symbol on the map, and walk to that place. When they arrived at that location, the story began.

During the test, the three evaluators followed the participants, each with a different role. The evaluation leader introduced the participants to the system and handed them necessary papers, i.e. the synopsis of their character and the context of the storyline. This person was also responsible for the technical aspects of running the prototype system reliably. A second evaluator recorded everything on video and also carried the 'wireless access point' laptop in a backpack. The third evaluator played the role of the "wizard" and was in control of triggering different aspects of the system, including location awareness and image recognition by the PDA. This was done without the participants' awareness. All three evaluators were responsible for making in-situ observations of the participants interacting with the system and making notes immediately afterwards.

After the field trial, a debriefing interview was held with participants. Together with observational findings from the field these interviews form the basis of our understanding of the user experience of the prototype system in use. The interview questions covered different aspects of the system including overall experience, storyline and collaboration.

\section{FINDINGS AND DISCUSSION}

In the following sections we report and discuss findings from our field trials.

\subsection{Collaborating with each other}

Prior to running the field trial, we only gave the participants a minimum of information about using the system to see if the interaction was intuitive. We decided that having to work things out for themselves would increase the need for collaboration between participants. Generally, given this limited guidance, we were pleased to note that the participants communicated in the places that we expected them to. They all realized very early on in the experience that they needed to collaborate with each other to get through the story.

We observed that the participants naturally worked together to solve the mystery. This was especially true after they discovered early that they were being given different and complementary information. We had expected this to happen, but the level of sharing detail was less than we had anticipated. Mostly they just gave each other a brief outline of what they had learned during their discourse as they walked together to the next location. This may have been due to the fact that the system did not specifically prompt them to stop and collaborate. It did not set aside specific places and times for this as a part of the storyline, so it was done when possible while on the move. However, because moving physically through the city involved negotiating real traffic and other people as well as navigating using the paper map and street signs, there was often not much opportunity for discussion and reflection on the clues given. The participants did however talk a lot to each other when they had story related questions, were trying to find their way using the symbols and the map, and when they faced technical issues - interestingly, in these situations problems were mostly solved by helping each other without turning to the evaluators.

The way that the system was designed meant that it delivered particular story discourses to the two participants in response to their interactions with the system. Each participant could choose to question a particular witness in a location or not, and they could ask one or more questions. They could search for hotspots on the screen or respond to physical props in any order that they chose. The downside of this flexibility meant that one detective could be finished looking for clues at a place before the other. This was a problem for the idle participant who tended to become bored as their partner was occupied with their own screen and audio, and therefore not open for interruptions or chat. At the same time they could not do anything themselves until their partner had finished, as both participants needed to finish their interactions before being provided with their part of the symbol needed to move on to the next scene.

Nevertheless, in the interviews, all participants agreed that a real strength of this system compared to similar computer games and city guides that they had used, was the close and necessary collaboration between two participants. They enjoyed the interpersonal social aspects of this experience as much as the interaction with the system. Some of the participants even suggested that using the system should require even more collaboration between the two detectives.

\subsection{Indexing to the surrounds}

In the system we used a picture of a place displayed on the PDA to indicate that participants had reached the location for the next 
episode of the story to commence. This use of indexing between the system and the real world to confirm for participants that they had decoded the map symbols and used the map correctly to move to the next location was found to be intuitive and clearly understood. We also noted that participants used the picture to guide themselves to the exact spot, indexing between the picture and their surroundings until their orientation and location in the physical space matched the picture on their screen.

In some locations a sequence of photographs was used to move people around a place in a more fine-grained way. The participants responded well to this by moving in time with the sequence of photographs and positioning themselves at different specific spots while the scene was played out. There were no written or spoken instructions to do so, the participants just naturally moved with the images. The participants reported that this was a more compelling way to move people around than responding to a set of mechanistic instructions, and that it helped them become more intertwined with the virtual environment provided by the narrative.

\subsection{Augmenting reality}

In using physical indexicality to get participants to align the image on their PDA with their physical surroundings we were also able to augment parts of their surroundings by superimposing characters and objects to support key elements of the story. This made use of peoples' abilities to transpose the digital overlays and imagine them overlaying the real world scene that they were located in, thus connecting story elements with the participant's immediate environment. This was especially important in the opening scene where users were led through a dark alleyway to the point where the detectives first view the body of the murdered Nun, Hanne. On arriving at the doorway where local police discovered the nun, a digital image of the dead Nun is overlaid onto a photograph of that doorway from that exact spot. It was reported by the participants, that effects like this made the storyline all the more poignant and imaginable.

\subsection{Handling the physical props}

We added the physical props into the story to see if they would enhance or hinder the experience. As it turned out, the physical props were very well received. They added tangible, playful and at the same time realistic aspects to the experience. However, the practicalities of actually handling them during the story experience proved to be troublesome. Firstly, it was difficult for participants to hold a PDA and a PDA pen each, while trying to retrieve and open envelopes from the shoulder bag, while on the move. This was especially true since we were not able to get wireless headsets for the demonstration, adding the messiness of an unsecured wire between the PDA and the headset. This made it difficult for participants to pass the PDA over to their partner to take charge of the props. This problem was exacerbated by the fact that these tests took place in Denmark in winter, so all participants were necessarily wearing big woolly gloves.

In a dedicated story environment, physical props could form part of the setting where the story takes place. Notices could be posted to pinup boards, signs attached to tree trunks, news papers with pertinent headlines left on park benches - but in the everyday city this is was not possible, all props had to be carried by the participants throughout the experience. This meant that they were encumbered by a large shoulder bag to carry the physical props. In interviews, participants complained that the volume of props that had to be carried around through the city, as well as PDAs and PDA pens was a bit too much to handle comfortably. In solving this problem, perhaps we could have done more with digital representations of these props in the system, but we felt that some things, like physically placing together two torn parts of a love letter were an important tactile part of the collaborative story building experience, and a small PDA screen would not add the same feeling of intrigue.

All in all, participants responded very favourably to the use of props. They said that it "made it more real", and added that the props could have enhanced the experience even more if they had been even more central to the story line and acted as vital pieces of evidence.

Participants were also fascinated by the use of physical props as input devices to the PDAs. They were happy to believe that if they held a piece of evidence up to the screen of the PDA it was able to "see" what that evidence was. In fact, one participant even decided this was done through RFID type devices, and when requested to hold a particular prop to the screen simply held up the whole shoulder bag, in the hope that that would suffice so they would not have to struggle with opening the bag and the envelope inside to retrieve the prop. Even though we had used the Wizard of $\mathrm{Oz}$ technique, and it was not technically possible in our system, this interaction method was believed and enthusiastically approved of.

\subsection{Knowing where you are}

All participants were convinced that the system was location aware, and enjoyed that part of the experience. They believed that the PDA was keeping track of their geographical location, and when interviewed expressed the feeling that this quality of the system allowed them to focus on the storyline, and gave them the power to command and interact with the system by simply moving.

In this way, the Wizard of $\mathrm{Oz}$ techniques that we used worked well in supporting a realistic experience with the system and all teams were very surprised when it was revealed to them at the end of the field trial the parts of the technology that had been "faked", especially the system knowing their current location,

\subsection{Experiencing the story}

It was clear in the interviews that all participants found the storyline interesting, and expressed a high motivation to reach the end of the story and to find out who killed Hanne Holmgaard. The general response to the concept of a story based tour of a city was positive, although one participant was quite candid in telling us that the choice of genre of murder mystery was not his thing, but that he could imagine people who enjoyed solving mysteries and role playing would love this system and find it very exciting.

Moving around a city was an important part of the experience. Participants all enjoyed walking through the city of Aalborg, in fact current residents of Aalborg claimed that they had learned new things about their city. For example, the existence of the Aalborg Convent, hidden near the central city shopping precinct, and its historical associations with the Danish resistance during World War II had not previously been known to any of the participants. 
The use of audio in the experience was very popular. Participants said they liked the recorded character voices and the sound effects, such as the sound of rain in the opening scene. They said that the audio created an atmosphere that blended with the actual sounds of the city around them and made the story really come to life. They did state that where there was a lot of dialogue it was difficult to maintain concentration, and in those cases would resort to focusing on those pieces of text and questions that were displayed in the screen. Given the noisy environment of a real city, we were not surprised by this comment, and it was for this reason that we supplemented all spoken dialogue with text on the screen.

The use of elements of the participants physical surrounds tied into the storyline was well received. In the interviews, most participants said they would have liked to have had to investigate their surroundings even more, for example an etching on a stone wall, looking for small details as clues. They felt that this would not only have provided them with a variation from focusing on interactions with the PDA display, but also facilitated more face-to-face, and fun, interactions with their partner. They felt that this would have added to the enticing experience of the blurring of the boundary between fact and fiction.

\section{CONCLUSIONS}

Making interactive stories and relating storytelling to locations are not new ideas on their own. Many of the creative arts, such as cinematography, writing and performance art, already combine factual and fictional elements to create compelling user experiences through stories. What is new and innovative here is providing this type of media content over the mobile Internet in a way that responds dynamically to the users' locations and to their movements through physical space.

People are indeed keen to experience stories while on the move, and they find the intersections between fact and fiction, physical space and digital space enticing, engaging and motivating. Collaborating with other people engaged in the same fictional space enhanced this experience and interactions with people, places and the plot satisfied users' desire for escaping reality.

In the introduction we posed a series of questions to inspire reflection on what might constitute the fictional (nonfunctional) requirements of a mobile location based service. In designing, deploying and studying the use of our location-based storytelling system in an urban environment, we have explored these questions empirically and come closer to an understanding of the different potentials and challenges for this class of location-based services.

\section{REFERENCES}

1. Abowd, G., Atkeson, C., Hong, J., Long, S., Kooper, R., and Pinkerton, M. Cyberguide: A mobile context-aware tour guide. Wireless Networks, 3 (1997), 421-433.

2. Benford, S., Crabtree, A., Flintham, M., Drozd, A., Anastasi, R., Paxton, M., Tandavanitj, N., Adams, M., and Row-Farr, J. Can You See Me Now? ACM TOCHI, 13, 1 (2006), 100-133.

3. Benford, S., Seager, W., Flintham, M., Anastasi, R., Rowland, D., Humble, J., Stanton, D., Bowers, J., Tandavanitj, N., Adams, M., Row-Farr, J., Oldroyd, A., and Sutton, J. (2004) The error of our ways: the experience of self-reported position in a location-based game, Proceedings of UbiComp 2004, Springer, London, 2004, $70-87$.

4. Bjork, S., Falk, J., Hansson, R., Ljungstrand, P. Pirates! Using the Physical World as a Game Board. In Proceedings of Interact 2001. IOS Press, Netherlands, 2001.

5. Blythe, M., Reid, J., Wright, P., and Geelhoed, E. Interdisciplinary criticism: analysing the experience of riot! a location-sensitive digital narrative. Behaviour \& Information Technology, 25, 2 (2006), 127-139.

6. Brown, D. The Da Vinci Code. Bantam Books, UK, 2003.

7. Cheverst, K., Davies, N., Mitchell, K., Friday, A., and Efstratiou, C. Developing a Context-aware Electronic Tourist Guide: Some Issues and Experiences. In Proceedings of CHI 2000. ACM Press, New York, 2000, 17-24.

8. Ericsson (2007) The 2006 Australian Survey. Ericsson Consumer and Enterprise Lab. 11 January 2007, http://www.ericsson.com/au/ericsson/press/2006/Consume r_Lab_2007_public.pdf.

9. Gaver, W., Beaver, J., and Benford, S. Ambiguity as a Resource for Design. In Proceedings of CHI 2003. ACM Press, New York, 233-240.

10. Greenwood, K. Earthly Delights. Allen \& Unwin, Australia, 2004.

11. Greenwood, K. Heavenly Pleasures. Allen \& Unwin, Australia, 2005.

12. Greenwood, K. Devil's Food. Allen \& Unwin, Australia, 2006.

13. Gustafsson, A., Bichard, J., Brunnberg, L., Juhlin, O., and Combetto, M. Believeable environments - Generating interactive storytelling in vast location-based pervasive games. In Proceedings of ACE 06. ACM Press, New York, 2006, Article no. 24.

14. Kjeldskov J. and Paay J. Public Pervasive Computing in the City: Making the Invisible Visible. IEEE Computer, 39, 9 (2006), 60-65.

15. Laursen, I. (1995): Det gamle Aalborg på vrangen. Eget forlag. ISBN: 87-985718-8.

16. Malaka, R., Schneider, K., and Kretschmer, U. StageBased Augmented Edutainment. In LCNS 3031 (2004), 5465.

17. Nisi, V., Wood, A., Davenport, G., and Oakley, I. Hopstory: an Interactive, Location-based Narrative Distributed in Space and Time. In Proceedings of TIDSE 2004. Springer, Berlin, 2004, 132-141.

18. Oppermann, R. and Specht, M. A Context-sensitive Nomadic Information System as an Exhibition Guide. In Proceedings of HUC2K. Springer-Verlag, London, 2000, 127-142

19. Paulos, E and Beckman, C. Sashay: Designing for Wonderment. In Proceedings of CHI 2006. ACM Press, New York, 2006, 881-884.

20. Piekarski, W. and Thomas, B. ARQuake: The Outdoors Augmented Reality System. Communcations of the ACM, 45, 1 (2002), 36-38. 
